\title{
A CONTRIBUIÇÃO TEÓRICA DE FRANZ HINKELAMMERT AO PROJETO ÉTICO DE LIBERTAÇÃO FORMULADO POR DUSSEL
}

\author{
Cláudia Honório* \\ Heloísa da Silva Krol ${ }^{* *}$
}

\begin{abstract}
RESUMO
O presente estudo debruça-se sobre a contribuição teórica de Franz Hinkelammert para a ética da libertação formulada por Enrique Dussel. Hinkelammert trata da factibilidade ou realizabilidade dos atos. O verdadeiro e válido deve ser possível, na prática. Hinkelammert afirma a impossibilidade de apreensão da realidade, ressaltando a limitação das ações humanas. Não se pode pensar em utopias ingênuas, e sim no que é possível fazer. Na definição desse possível, a razão estratégico-instrumental é útil e necessária, mas insuficiente. A importância da obra de Hinkelammert é inserir um conteúdo ético na racionalidade instrumental, valorizando a vida do sujeito e impedindo que os fins sejam alcançados por qualquer meio. Só é possível o que torna a vida possível. Assim, nota-se forte contribuição para a concretização do objetivo da ética da libertação.
\end{abstract}

Palavras-chave: ética da libertação - Enrique Dussel - factibilidade - razão instrumental - Franz Hinkelammert.

\begin{abstract}
SUMÁRIO: INTRODUÇÃO; 1 A ÉTICA DA LIBERTAÇÃO; 2 CONSIDERAÇÕES DE FRANZ HINKELAMMERT; 2.1 CRÍTICA DA RAZÃO UTÓPICA ÀS CATEGORIAS DO PENSAMENTO SOCIAL; 2.2 O PAPEL DAS UTOPIAS: O POSSÍVEL DETERMINADO A PARTIR DO IMPOSSÍVEL; $2.3 \mathrm{O}$ PRINCIPIO DA IMPOSSIBILIDADE NA TEORIA DE POPPER; 2.4 A REALIDADE TRANSCENDE A TEORIA; 2.5 A CONSIDERAÇÃO DO SUJEITO VIVO E DE SUAS NECESSIDADES; 2.6 O AUTOMATISMO DO MERCADO E A NECESSIDADE DE PLANEJAMENTO ECONÔMICO; 2.7 UM ESPAÇO
\end{abstract}

\footnotetext{
* Bacharel em Direito pela UFPR. Especialista em Direito Constitucional pela UniBrasil. Mestranda em Direito pela UFPR. Bolsista da CAPES. E-mail: claudia.honorio@ hotmail.com

** Bacharel em Direito pela UFPR. Mestre e Doutoranda em Direito do Estado pela UFPR. Bolsista do CNPQ. E-mail: helo_krol@ hotmail.com
} 


\title{
A Contribuição Teórica de Franz Hinkelammert ao Projeto Ético de LIBERTAÇÃO FORMULADO POR DUSSEL
}

\author{
DE REFLEXÃO ENTRE O POSSÍVEL E O \\ IMPOSSÍVEL; 3 O APORTE TEÓRICO DE \\ HINKELAMMERT COMO MEDIAÇÃO NECESSÁRIA \\ À ÉTICA DA LIBERTAÇÃO; REFERÊNCIAS.
}

\section{INTRODUÇÃO}

$\mathrm{Na}$ presente abordagem enfrentar-se-á a questão da realização da norma verdadeira materialmente e válida formalmente. Ou seja, na perspectiva de Enrique Dussel, trata-se de discutir a questão da factibilidade, das condições ou circunstâncias concretas de sua efetiva possibilidade. Para tanto, é necessário partir para o estudo dos fundamentos do critério e do princípio de factibilidade. Tal tarefa terá como apoio a obra de um dos mais importantes autores latino-americanos contemporâneos - Franz Hinkelammert ${ }^{1}$.

\footnotetext{
${ }^{1}$ Hinkelammert nasceu em 1931 na Alemanha e vivenciou na adolescência o regime nazista, o que lhe marcou profundamente. Estudou economia, filosofia e teologia nas universidades de Hamburgo, Munster e Berlim. Em Berlim, doutorou-se em economia com a tese sobre $O$ desenvolvimento econômico da União Soviética. Morou no Chile a partir de 1963, mas teve que deixar o país em 1973. Nessa época, publicou Economia e revolução e Ideologias do desenvolvimento e dialética da história, $O$ subdesenvolvimento latino-americano e Dialética do desenvolvimento desigual. Nesses anos também aprofundou suas reflexões sobre as obras de Marx, Hayek, Popper e outros autores. Hinkelammert voltou à Alemanha e entre 1973 e 1976 foi professor da Universidade Livre de Berlim. Em 1976, publicou seu estudo sobre A radicalização da direita dos democratascristãos e retornou à América Latina. Primeiramente, exerceu a função de diretor do curso de Pósgraduação em Política Econômica da Universidade Autônoma de Honduras, depois foi professor e investigador do Conselho Superior Universitário da América Central e, posteriormente, instalou-se em São José da Costa Rica e criou o Departamento Ecumênico de Investigações. Desde então publicou um conjunto de investigações entre as quais se encontram As armas ideológicas da morte (1977), Crítica da razão utópica (1984), Democracia e totalitarismo (1987), A divida externa da América Latina (1988); A fé de Abraham e o Edipo ocidental (1989), Sacrifícios humanos e sociedade ocidental (1991), Cultura da esperança e sociedade sem exclusão (1995); O mapa do imperador (1996); O grito do sujeito (1998).
} 


\section{A ÉTICA DA LIBERTAÇÃO}

O momento atual é de "condições materiais não satisfeitas minimamente, com carências básicas não resolvidas pela economia de mercado capitalista, com crescente aumento da pobreza, miséria e fome de três quartos da população mundial."2 As contradições e exclusões sociais são evidentes e crescentes. A verdade empírica inafastável é a negação da vida humana em grande parte do mundo. A modernidade não realizou suas promessas de emancipação pela razão, igualdade, liberdade e fraternidade. Surge o dever de criticar.

Deve-se pensar a modernidade não só na perspectiva eurocêntrica de emancipação (lado positivo), mas também considerando a periferia, os sujeitos assujeitados, os efeitos negativos produzidos pela modernidade, ainda que não intencionais (lado negativo). Cabe repensar os aspectos negativos da modernidade, visando transformá-los, mantendo-se também o que a modernidade tem de positivo. Por isso a crítica não pode ser antimoderna ou pós-moderna, e sim transmoderna. É no panorama da transmodernidade que se desenvolve a ética da libertação, teorizada por Enrique Dussel, da qual se esboçarão as linhas gerais.

A ética em geral ocupa-se do binário bom/mau. Já a ética da libertação tem outro ponto de partida: a pretensão de bondade dos atos (entendidos em sentido amplo, como normas, instituições, sistemas etc.). Nesse sentido, um ato tem "pretensão de bondade quando as condições universais (momento material de verdade prática; o momento formal de validade consensual; e o momento da factibilidade da razão instrumental - todos os momentos que servem como mediação da produção, reprodução e desenvolvimento da vida humana) estiverem cumpridas e os efeitos negativos não-intencionais levados em conta." ${ }^{3}$

${ }^{2}$ LUDWIG, Celso Luiz. Da ética à filosofia política crítica na transmodernidade: reflexões desde a filosofia de Enrique Dussel. In: FONSECA, Ricardo Marcelo (org). Repensando a Teoria do Estado. Belo Horizonte: Fórum, 2004. p. 285.

${ }^{3}$ Ibidem, p. 324. 


\section{A Contribuição Teórica de Franz Hinkelammert ao Projeto Ético de LIBERTAÇÃO FORMULADO POR DUSSEL}

Diante da negação da vida, surge o dever e a responsabilidade ética pelas vítimas do sistema. Considerando essas premissas, Dussel estrutura sua ética da libertação em seis momentos necessários.

O primeiro momento é material. Interessa o conteúdo - a vida humana como modo de realidade do sujeito ético (em toda sua dimensão existencial, concreta). Considera-se "desde o nível físico-biológico, histórico-cultural, econômico-político, ético-estético, político-social, místico-transcendental" ${ }^{4}$. A vulnerabilidade da vida pede que sejam respeitados limites e impõe conteúdos, "que vão desde a necessidade de alimentos, casa, segurança, liberdade, valores, identidade cultural e soberania até as mais sofisticadas manifestações culturais nas variadas formas civilizatórias." ${ }^{5}$ A vida humana é repleta de necessidades, que são universais (as culturas são concreções particulares dessas necessidades). A vida é a condição de possibilidade de tudo o mais, por isso deve-se mantê-la.

Desses fatos, extrai-se, por fundamentação material, o princípio ético-material: "aquele que atua eticamente deve (como obrigação) produzir, reproduzir e desenvolver auto-responsavelmente a vida concreta de cada sujeito humano, numa comunidade de vida" 6 .

O segundo momento é formal. O que deve ser executado para promover o conteúdo acima deve ser decidido coletivamente. Significa dizer que serão válidos apenas os conteúdos que forem acolhidos intersubjetivamente. O conteúdo verdadeiro não pode se impor sem uma forma válida; do mesmo modo, uma forma válida não pode se impor sem um conteúdo verdadeiro. Os dois momentos - material e formal interdependem-se.

O terceiro momento, fechando a tríade dos fundamentos da ética da libertação, é da factibilidade. Não basta que algo seja verdadeiro e válido; deve também ser

${ }^{4}$ Ibidem, p. 289.

${ }^{5}$ Ibidem, loc.cit.

${ }^{6}$ DUSSEL, Enrique. Ética da libertação - na idade da globalização e da exclusão. Petrópolis: Vozes, 2000, p. 143. 
realizável para que seja bom.

A factibilidade diz respeito à possibilidade (em diversos níveis: lógica, empírica, técnica, econômica e ética) do objeto na prática. Nem tudo é possível. Então, pelo critério da factibilidade, analisam-se as circunstâncias e efeitos da ação, consideram-se "as condições de possibilidade objetiva (materiais e formais, empíricas, técnicas, econômicas, políticas e outras) para que o ato seja efetivamente possível."7 Nessa seara, a razão estratégico-instrumental é útil e necessária, mas insuficiente. Deve estar sobredeterminada por exigências de verdade prática e de validade intersubjetiva. Os momentos interagem, fazendo com que a factibilidade seja o princípio ético de factibilidade: o que deve ser feito, por uma questão ética, considerando as possibilidades objetivas.

Os outros três momentos da arquitetônica do ético têm conotação crítica. Se antes se partia da afirmação da vida, agora se parte da negação da vida, tendo em vista a realidade de vítimas.

Como não há sistema perfeito, surgem vítimas, ainda que não intencionais. Mas as situações que impossibilitam o desenvolvimento da vida não podem ser eticamente aceitas. Reconhecida a vítima como ser humano com dignidade, surge a responsabilidade por essa vítima ${ }^{8}$, e, conseqüentemente, um dever ético de criticar o que causa a negatividade. É o momento da crítica material, que leva à transformação para afirmar a vida.

O quinto momento é da crítica formal. Para efetivar as transformações para negar a negação da vida (e, portanto, afirmá-la), exige-se um procedimento válido moralmente. O procedimento discursivo intersubjetivo deve ser pensado a partir da

${ }^{7}$ LUDWIG, op. cit., p. 302-303.

${ }^{8}$ A ética exige solidariedade, que não é apenas tolerar o outro, a vítima. Por isso Dussel vincula o reconhecimento do outro a um dever ético de agir, uma responsabilidade. Essa responsabilidade, contudo, não é direta, no sentido de que ao reconhecer alguém em situação de miséria eu devo me sentir pessoalmente responsável a ponto de recolher a vítima em meu lar e dar-lhe as condições necessárias para bem viver. Trata-se da responsabilidade da sociedade como um todo, de alguma forma, por aquela vítima. A responsabilidade deve ser entendida nesse sentido: como integrante do sistema que causa negatividade, sou responsável pelas vítimas desse sistema. 


\section{A Contribuição Teórica de Franz Hinkelammert ao Projeto Ético de LIBERTAÇÃO FORMULADO POR DUSSEL}

validade anti-hegemônica, possibilitando a participação das vítimas, formando nova comunidade de comunicação, em que os dissensos são válidos. Extrai-se um dever ético de formulação, pelas vítimas, de dissensos que (i) denunciem os efeitos negativos dos consensos hegemônicos sobre a vida, e (ii) anunciem alternativas de transformação, com a imaginação de utopias factíveis.

O último momento do projeto de ética da libertação é da nova factibilidade. Aqui se cogita da possibilidade ou impossibilidade de frentes de libertação que viabilizem os dissensos para negar a negação (em que se perquirem a fragilidade do sistema dominante, a força e as possibilidades de ação dos sujeitos da ação libertadora, e a conjuntura objetiva do momento). Trata-se da práxis de libertação factível, que transforme a realidade para a superação das negatividades. Afirmada a factibilidade das alternativas, opera-se a transformação ou revolução. Aquele que age eticamente deve (i) libertar a vítima por meio de uma transformação factível do que impede a vida da vítima ou exclui da participação intersubjetiva, e (ii) construir novos meios em que ou por meio dos quais as vítimas possam viver plenamente.

Em síntese, parte-se da afirmação da vida, sendo a vida fonte de todos os direitos. Por isso deve ser produzida, reproduzida e desenvolvida em todos os atos. As ações éticas precisam ter esse conteúdo para serem verdadeiras; ser acolhidas intersubjetivamente para serem válidas; e considerarem as condições de possibilidade para serem factíveis. E diante da negação da vida na realidade, deve-se criticar o sistema vigente, com conteúdo que explicite as vítimas e possibilite a transformação. A crítica deve abarcar os dissensos e possibilitar a participação das vítimas no debate, para ser válida, e considerar a factibilidade da libertação. Seguindo esses passos ter-seá a libertação da negatividade e a ação ética, com pretensão de bondade. Esses pilares da ética da libertação orientam a pretensão de eticidade nas diferentes esferas concretas da vida, como a política e o direito, por exemplo. 


\section{CONSIDERAÇÕES DE FRANZ HINKELAMMERT}

\subsection{CRÍTICA DA RAZÃO UTÓPICA ÀS CATEGORIAS DO PENSAMENTO SOCIAL}

O que caracteriza basicamente o pensamento de Hinkelammert é seu caráter crítico emancipatório, já que aborda suas temáticas não apenas por sua importância dentro do debate científico-social, mas também porque estão diretamente ligadas as formas de dominação, opressão e controle social ${ }^{9}$.

Assim, a partir da obra de Hinkelammert - em especial seu livro Crítica da Razão utópica ${ }^{10}$ - analisar-se-á o critério e o princípio da factibilidade, cujas linhas gerais já foram enunciadas na primeira parte deste artigo.

O título do livro "Crítica da razão utópica" remete à obra kantiana "Crítica da razão pura", pois Hinkelammert acredita que a crítica à razão utópica só pode ser transcendental. E explica o autor que seu trabalho é necessariamente abstrato, porque sem o abstrato não se pode perceber o concreto (vez que a percepção requer interpretação em termos abstratos).

Nesta obra, Hinkelammert afirma que "Todos os pensamentos sociais do século passado e até de séculos anteriores nos legaram a tradição de uma espécie de ingenuidade utópica que recobre como um véu a percepção da realidade social."11 Parte-se do pressuposto de que há uma escada que leva da terra ao céu (mundo perfeito), e as teorias se esforçam para encontrar essa escada.

No século XX, essa ingenuidade utópica entrou em crise, e desenvolveram-se

\footnotetext{
${ }^{9}$ Segundo David Sanchez Rubio, Hinkelammert se dedica há anos a desvendar os "espelhos" que o Ocidente construiu e utiliza para ver a realidade. Principalmente, preocupou-se em colocar luz sobre as principais opacidades que provocam não apenas o obscurecimento da vida, mas também o seu rechaço e sua eliminação (RUBIO, David Sanchez. Resenha. Revista Crítica Jurídica, n. 20, p. 268, jan./jul./2002).

${ }^{10}$ HINKELAMMERT, Franz. Crítica da razão utópica. São Paulo: Paulinas, 1986.

${ }^{11}$ Ibidem, p. 5.
}

Formatado: Português (Brasil) 


\section{A Contribuição Teórica de Franz Hinkelammert ao Projeto Ético de LIBERTAÇÃO FORMULADO POR DUSSEL}

pensamentos antiutópicos. Mas ao invés de superar as utopias e criticar a razão utópica, criou-se uma nova utopia camuflada. Hinkelammert dedica-se justamente a criticar a razão utópica. A crítica é tratada não como ignorar ou rejeitar um pensamento, mas sim partir desse pensamento, revelando seus limites e abrindo horizontes para, por fim, superá-lo. São analisados os modelos teóricos do conservadorismo, do neoliberalismo, do socialismo e do anarquismo, para concluir que todos eles apresentam utopias que não são realizáveis ${ }^{12}$.

Primeiramente, Hinkelammert analisa o pensamento conservador a partir da obra de Peter Berger e observa que esse tem como base uma realidade precária (realidade empírica de mundos construídos socialmente) que constitui uma ordem social, tratada essa ordem social exclusivamente como ordem de instituições ${ }^{13}$.

Para Berger, a ordem social objetiva apresenta implicitamente uma legitimidade em virtude da sua factibilidade objetiva. Contudo, isso não apaga o fato da ordem social ser uma ordem precária e como ordem precária é uma ordem questionada. Então, surgem funções sociais cuja finalidade é a manutenção da ordem social como mundo socialmente construído, impedindo o questionamento da ordem social legítima. Berger trabalha com conceitos limites de plausibilidade perfeita e atividade de legitimação. A atividade de legitimação indica como seu contrário a plausibilidade perfeita. Quanto maior é a ilegitimidade do nomos, maior é a sua atividade legitimadora. O conceito limite descreve o ponto de legitimidade absoluta, no qual não há nenhuma ilegitimidade do nomos e, portanto, também nenhuma atividade de legitimação. Essa é a utopia buscada por Berger e que marca a ingenuidade utópica do pensamento conservador ${ }^{14}$.

Já as categorias neoliberais são analisadas por Hinkelammert com base no pensamento de Friedrich Hayek, que sustenta a legitimidade apenas de uma sociedade

\footnotetext{
12 Ibidem, p. 6-7.

${ }^{13}$ Ibidem, p. 23, 31, 32, 44.

${ }^{14}$ Ibidem, p. 24.
} 
específica contra outras sociedades (legitimação da sociedade burguesa) ${ }^{15}$. O pensamento neoliberal parte do mercado como realidade. $\mathrm{O}$ mercado consiste num conceito empírico e partir daí o pensamento liberal elabora seu quadro de categorias de modo polarizado, apresentando conceitos limites que remetem à noção de caos e mercado perfeito ou concorrência perfeita. Mas tanto o caos como a concorrência perfeita são conceitos não-empíricos que englobam a realidade empírica, limitando-a. Trata-se de conceitos transcendentais em relação aos quais a realidade é interpretada, mas não são factíveis, são arbitrários ${ }^{16}$.

Para Hinkelammert, o pensamento neoliberal repousa sobre uma confusão, pois sustenta tal tendência empírica em um conceito limite e transcendental, nãofactível $^{17}$.

O pensamento anarquista - analisado a partir dos artigos de Ricardo Flores Magon - parte também de uma realidade precária, que é a realidade material de trabalho para satisfação das necessidades, realidade que se encontra subjugada pelo sistema institucional (o sistema de propriedade e o Estado). Apresenta um enfoque bipolar: a realidade presente é uma ordem de escravidão, ao passo que uma ordem de liberdade é algo que ainda está por construir ${ }^{18}$.

Para Flores, o homem é escravo do capital que o domina. A lei e a moral burguesas servem para defender o proprietário daquilo que ele considera crime. Como o Estado defende a lei, o homem passa a ser escravo do trabalho e, para Flores, a única alternativa é negar toda a autoridade. Segundo Hinkelammert, trata-se de alternativa

${ }^{15}$ Ibidem, p. 47.

${ }^{16}$ Ibidem, p. 48.

${ }^{17}$ Note-se que embora Hayek sustente sua tese com base em em argumentos utópicos nãofactíveis, no momento em que busca questionar a "utopia socialista" (projeto de uma sociedade sem relações mercantis) vale-se da noção de impossibilidade. Para Hayek, a utopia socialista só seria possível se, pelo menos, um indivíduo tivesse conhecimento perfeito do conjunto de todos os acontecimentos. Mas afirma ser impossível que uma pessoa ou instituição tenha conhecimento perfeito que torne possível um planejamento que possa substituir o mercado em função de atribuição dos recursos. Como o socialismo tenta efetuar o planejamento central capaz de substituir o mercado tenta o impossível. E, assim, para Hayek o socialismo é irracional (Ibidem, p. 57).

${ }^{18}$ Ibidem, p. 95, 96. 


\section{A Contribuição Teórica de Franz Hinkelammert ao Projeto Ético de LIBERTAÇÃO FORMULADO POR DUSSEL}

tão polarizada e não-factível quanto à teoria conservadora e neoliberal e o grande problema reside na transição dessa realidade subjugada do presente para o futuro, pois não se pode pensá-la no marco anarquista por meio da mediação de instituições ${ }^{19}$.

No quadro do pensamento soviético, há uma forte influência do pensamento anarquista - principalmente em Marx. Por outro lado, há diferenças profundas, tendo em vista que o pensamento marxista concentra-se na problemática da mediação institucional entre ação revolucionária presente e construção da sociedade futura ${ }^{20}$.

Essa mediação é pensada a partir do poder político do Estado. Então, o Estado aparece como uma ponte institucional entre a sociedade capitalista e a sociedade socialista. A liberdade econômica assegurada posteriormente possibilitaria a própria abolição do Estado e surgiria o comunismo ${ }^{21}$.

Com efeito, o centro da crítica neoliberal ao pensamento socialista reside na afirmação da impossibilidade de uma economia ser organizada sem recorrer a relações mercantis e basear-se numa modalidade de planejamento perfeito. Contudo, ao contrário do que afirma principalmente Hayek, verifica-se que a tentativa de realizar o impossível não leva ao caos, mas ao conhecimento dos efetivos limites da possibilidade $^{22}$.

E, assim, embora o processo real de planejamento não seja factível em termos exatos o é em termos aproximados. Dessa forma, Hinkelammert observa que uma agressão pura e simples ao pensamento utópico também pode trazer consequiências equivocadas, tais como a defesa de que nenhuma utopia possa existir ${ }^{23}$.

\footnotetext{
${ }^{19}$ Ibidem, p. 98-99, 101, 123-126.

${ }^{20}$ Ibidem, p. 129-130.

${ }^{21}$ Ibidem, p. 130-131.

${ }^{22}$ Ibidem, p. 135.

${ }^{23}$ Ibidem, p. 140.
} 


\subsection{O PAPEL DAS UTOPIAS: O POSSÍVEL DETERMINADO A PARTIR DO IMPOSSÍVEL}

Embora exista também uma ingenuidade utópica no pensamento socialista, uma das primeiras e principais críticas às abstrações e utopia da sociedade burguesa foi realizada por Marx para quem toda sociedade burguesa é impossível. Pelo fato das abstrações perseguidas pela sociedade burguesa desembocarem em algo impossível, produzem a sua própria destruição. E essa impossibilidade se dá na medida em que as relações mercantis não dão conta da tarefa de levar ao progresso humano, mas apenas asseguram uma evolução técnica cujo progresso sacrifica a vida humana em nome da glória mercantil ${ }^{24}$.

Então, Marx apresenta o argumento da impossibilidade dessa política e afirma que a sociedade capitalista é impossível porque é autodestrutiva. Defende ainda que o progresso só pode ser orientado em função da vida humana se for controlado e dominado em função da própria vida humana e, para tanto, é preciso superar as abstrações vinculadas às relações mercantis e também as próprias relações mercantis ${ }^{25}$.

Segundo Hinkelammert, o central na discussão sobre a sociedade capitalista feita por Marx é que transforma toda a visão da política e seu realismo em discussão sobre o âmbito do possível. Assim, a política não se orienta primordialmente por éticas, mas sim por relações meio-fim. Antes de qualquer juízo ético apresenta-se o juízo fático, que diz que algo pode ser eticamente obrigatório apenas quando também é factível $^{26}$.

O ponto decisivo é a polarização entre o possível e o impossível. E, a partir de Marx, o critério de limite entre o possível e o impossível é o critério da reprodução da vida humana real e concreta. A sociedade que não pode acelerar tal reprodução é a

\footnotetext{
${ }^{24}$ Ibidem, p. 12-13

${ }^{25}$ Ibidem, p. 13.

${ }^{26}$ Ibidem, p.14.
} 


\section{A Contribuição Teórica de Franz Hinkelammert ao Projeto Ético de LIBERTAÇÃO FORMULADO POR DUSSEL}

sociedade impossível ${ }^{27}$.

A questão do possível em política não perdeu sua validade, embora tenha mudado de sentido. Para Hinkelammert, Marx tinha razão quando afirmava que a sociedade capitalista está estruturada de modo tal que dirige o poder do progresso humano contra a própria vida humana e seu desenvolvimento. Mas Weber também tinha razão quando afirmou que as relações mercantis são insubstituíveis ${ }^{28}$.

Dessa forma, verifica-se que a análise do impossível se apresenta em sentido diferente da tradicional discussão ideológica, pois o impossível não é tanto o que o outro faz, mas sim aquilo que ele crê fazer. O que se faz nunca é impossível, mas aquilo que se crê fazê-lo pode sê-lo. De outro lado, a vontade pura - sem consideração de sua factibilidade - sempre aspira ao impossível. O possível é o resultado da submissão do impossível ao critério da factibilidade. Então, tem-se o seguinte: concebe-se o impossível para, por meio da experiência e da análise da factibilidade, conhecer o possível ${ }^{29}$.

A ilusão de poder construir uma sociedade perfeita é uma ilusão transcendental que distorce o realismo político, e essa ilusão transcendental só pode ser superada pela crítica que revele o caráter transcendental dos conceitos de perfeição, mas sem pretender renunciar a eles. Quando se procura solucionar os problemas concretos, pode-se pensar sua solução com base em uma resposta perfeita para assim poder pensar realisticamente em que grau é possível aproximar-se de tal solução, em termos de sua possibilidade. Como arte do possível, a política contém, portanto, o que se denomina a crítica à razão utópica, que não constitui em si uma rejeição do utópico, mas sim a sua conceituação transcendental ${ }^{30}$.

\footnotetext{
${ }^{27}$ Ibidem, p. 15.

${ }^{28}$ Ibidem, p. 15-16.

${ }^{29}$ Ibidem, p. 17.

${ }^{30}$ Ibidem, p. 18-21.
} 
Revista Eletrônica do CEJUR, Curitiba-PR, a. 2, v. 1, n. 3, ago./dez. 2008

\subsection{O PRINCÍPIO DA IMPOSSIBILIDADE NA TEORIA DE POPPER}

Karl Popper é um dos importantes autores que se preocupou em realizar uma crítica do utópico, embora existam incoerências na sua tese, como as apontadas a seguir $^{31}$.

As teorias de Popper são geradas a partir de um princípio comum que é central de toda sua teoria sobre a sociedade, qual seja: o principio da impossibilidade, que consiste na afirmação empírica sobre a índole da impossibilidade empírica absoluta ${ }^{32}$.

Trata-se de princípio retirado da teoria econômica de Hayek e pode ser resumido na tese de que toda ação social humana é limitada pelo fato de que o conjunto dos conhecimentos humanos não é centralizável em uma só cabeça ou instância. Assim, é impossível o conhecimento perfeito de todos os fatos da relação social humana interdependente. Essa impossibilidade vale tanto para cada homem quanto para qualquer grupo humano e, por conseguinte, para toda instituição humana ${ }^{33}$.

Popper expressa esse princípio em termos categóricos e sustenta que se trata de uma impossibilidade lógica do conhecimento ilimitado ${ }^{34}$.

Não se trata de uma afirmação nova, a impossibilidade do conhecimento ilimitado, mas a conformação que isso assume nas ciências sociais revela algo de novo. Aparece como categoria de discernimento da ação social humana da qual se deriva a impossibilidade de qualquer ação humana, cuja realização exigisse tal

${ }^{31}$ Hinkelammert justifica a escolha de Popper como autor base para a reflexão por ter sido o primeiro a realizar uma crítica ao utópico, embora paralelamente a Popper, Ernst Bloch também seja um autor representativo da reflexão sobre o utópico. Contudo, Bloch não se preocupou em realizar a crítica do utópico, sendo, inclusive, ingênuo nesse ponto, segundo Hinkelammert. Assim, optou por dialogar com Popper, que, embora imbuído de intenções críticas, também acabou recaindo em uma ingenuidade utópica (Ibidem, p. 8).

${ }^{32}$ Ibidem, p. 170.

${ }^{33}$ Ibidem, p. 171.

${ }^{34}$ Idem. 


\section{A Contribuição Teórica de Franz Hinkelammert ao Projeto Ético de LIBERTAÇÃo FORMULADO POR DUSSEL}

conhecimento ilimitado ${ }^{35}$.

Popper assume o juízo apodítico da impossibilidade. Então, Hinkelammert cuida de analisar o status metodológico desse princípio da impossibilidade diante da metodologia de Popper, a qual só admite na ciência enunciados falseáveis que podem ser pronunciados nos termos de um ainda não. Todavia, o princípio da impossibilidade nega esse ainda não e tem a forma de enunciado não-falseável ${ }^{36}$.

Dessa maneira, se o enunciado da impossibilidade afirma um ainda não (por exemplo, ainda não é possível o homem viajar a Vênus), não tem caráter apodítico e não serve para juízos em termos de categorias. Dessa forma, demonstrar que o princípio da impossibilidade é falseável já significa demonstrar que ele é falso. $\mathrm{O}$ princípio geral empírico da impossibilidade se afirma em sua validade, precisamente por sua afirmação de que não é falseável ${ }^{37}$.

Para encobrir esse fato que invalida a sua metodologia, Popper designa tais impossibilidades como impossibilidades lógicas. ${ }^{38}$

Para demonstrar as incoerências de Popper, Hinkelammert trabalha com suas teorias do planejamento econômico, da concorrência do mercado e do processo de institucionalização.

Por exemplo, a teoria do planejamento econômico de Popper é uma crítica do planejamento e constitui o núcleo de seu conceito de utopismo e de sua denúncia ${ }^{39}$.

Popper sustenta que o planejamento do conjunto social é impossível porque isso pressupõe um conhecimento ilimitado. A impossibilidade lógica do planejamento

\footnotetext{
${ }^{35}$ Idem.

${ }^{36}$ Idem.

${ }^{37}$ Ibidem, p. 171-172.
}

${ }^{38}$ Assim, Hinkelammert sustenta que Popper em suas analises teóricas sobre a empiria guiase por princípios metodológicos não explícitos, que não são compatíveis com a metodologia que ele defende explicitamente em suas analises metodológicas. Dessa maneira, no pensamento de Popper aparece uma contradição entre duas metodologias mutuamente excludentes.

\footnotetext{
${ }^{39}$ Ibidem, p. 172.
} 
(de todo planejamento) se dá porque é impossível planejar literalmente tudo na medida em que se possuem conhecimentos limitados ${ }^{40}$.

Para Hinkelammert esse argumento apresenta duas fraquezas. A primeira consiste na tese do caráter lógico da impossibilidade do planejamento total. Se a razão é a vigência de um princípio empírico geral da impossibilidade, tal impossibilidade não é lógica, mas fática. Segundo, quando Popper diz que a tentativa impossível da realização desse planejamento total desemboca na regressão infinita, afirma algo que não existe, pois se pode falar apenas em progressão infinita na medida em que o argumento de Popper refere-se a algo que acontecerá no futuro ${ }^{41}$.

Devido às incoerências do pensamento de Popper, sua teoria se apresenta limitada, pois o autor não consegue analisar a relação entre utopias impossíveis e metas possíveis. Popper separa o possível e o impossível em dois mundos, embora por força dos fatos sempre tenha que confundi-los de novo, porque tal separação efetivamente é impossível ${ }^{42}$.

\subsection{A REALIDADE TRANSCENDE A TEORIA}

Hinkelammert parte dessas premissas para pensar a factibilidade da reprodução da vida real. $\mathrm{O}$ autor ressalta que as ciências empíricas não podem falar da realidade sem que haja uma ação humana sobre essa realidade. E a ação humana depara-se com impossibilidades.

\footnotetext{
${ }^{40}$ Idem.
}

${ }^{41}$ Ainda, verifica-se que Popper tem uma visão arbitrária do planejador, pois o planejador para ele não tem nenhuma função que possa ser tratada objetivamente, pois se trata de um homem possuído pelo poder que camufla seu imenso desejo de poder com a exigência de planejamento. Então, Popper cria um mecanismo de agressão contra qualquer socialismo, pois considera todo planejamento utópico (Ibidem, p. 174).

${ }^{42}$ Ibidem, p. 189. 


\section{A Contribuição Teórica de Franz Hinkelammert ao Projeto Ético de LIBERTAÇÃO FORMULADO POR DUSSEL}

O sujeito aproxima-se da realidade e atua pretendendo determinados fins. À medida que se perseguem os fins, as impossibilidades são experimentadas. Apenas conhecendo essas impossibilidades pode-se falar do possível. O sujeito, assim, transcende a realidade e encontra nela o limite do possível. Sem essa transcendência, fica-se limitado ao existente. "Desse modo, transcender o possível é condição para conhecer o possível e, ao mesmo tempo, conhecer o possível é condição para transcender a realidade no marco do possível." ${ }^{43}$ É tentando superar limites que se conhecem verdadeiramente os limites; e para ir além dos limites deve-se considerar os limites existentes.

O pensamento transcende a realidade ao utilizar conceitos universais, sendo que, na verdade, os casos concretos são limitados. O próprio sujeito cognoscente é limitado, pois não consegue apreender todos os casos; logo, tenta fazê-lo por meio de conceitos universais.

A realidade, ilimitada, transcende a experiência e a teoria. Isso quer dizer que antes dos conceitos universais existe uma realidade ilimitada e também transcendental, que justamente por ser impossível de apreensão total, faz com que o sujeito busque conhecê-la por conceitos transcendentais, que superam, por sua vez, os casos que se pode observar ou experimentar. Se a totalidade dos fatos pudesse ser experimentada, não haveria necessidade de conceitos universais nem de ciência, pois se conheceria especificamente cada um dos objetos.

A realidade supera a teoria, por causa justamente das limitações do sujeito cognoscente. $\mathrm{O}$ sujeito não consegue apreender toda a realidade, por isso a teoria está sempre atrás. "Devido ao fato de a realidade superar a teoria, uma teoria científica nunca pode ser considerada como algo acabado, mas sim como um conjunto de hipóteses." 44

Assim, a realidade transcende a experiência. Frente à necessidade de aceder à

\footnotetext{
${ }^{43}$ Ibidem, p. 256.

${ }^{44}$ Citação de Miró (ibidem, p. 260).
} 
realidade, transforma-se a realidade em teoria, por meio dos conceitos universais.

Sabe-se que um sujeito puramente cognoscente não acessa a realidade; é preciso um sujeito atuante para testar possibilidades e conhecer teorias. A realidade se transforma em objeto de conhecimento das ciências empíricas porque o sujeito atua sobre a realidade. Desta atuação resultam os princípios da impossibilidade e, por dedução, as teorias gerais. "Em última instância, o sujeito cognoscente é o nome da capacidade reflexiva do sujeito atuante que reflete sua capacidade de ação por meio de conceitos universais" ${ }^{45}$.

Mas este sujeito que reflete é o sujeito da tecnologia. Tudo o que se pode conhecer é o que está ao alcance da tecnologia.

Parece, então, que pode ser escolhido qualquer dos caminhos tecnologicamente possíveis. Todavia há outra limitação dos meios possíveis (condicionante material de toda escolha). A vontade de realizar um projeto não pode superar as condições econômicas, materiais de possibilidade. Influi na escolha a escassez de meios para a realização. Assim, apenas alguns fins poderão ser escolhidos, dentre os tecnologicamente possíveis. "Independentemente da vontade humana e da capacidade de realização, as condições materiais da possibilidade, cujo conjunto é o produto social, obrigam à seleção dos fins efetivamente enfocados e realizados. Projetos tecnicamente possíveis só se tornam economicamente possíveis quando podem recorrer a um espaço nesse universo econômico do produto social e, portanto, quando podem contar com suas condições materiais de possibilidade." ${ }^{46}$ Assim, "Nenhum projeto pode se realizar se não for materialmente possível." ${ }^{47} \mathrm{~A}$ possibilidade não diz respeito apenas à tecnologia, mas sim à participação no produto social, o que permite vislumbrar que a factibilidade deve ser analisada em diversos níveis. E lembre-se que o que é possível em determinado momento econômico pode não ser em outro.

\footnotetext{
${ }^{45}$ Ibidem, p. 262.

${ }^{46}$ Ibidem, p. 263-264.

${ }^{47}$ Ibidem, p. 264.
} 


\section{A Contribuição Teórica de Franz Hinkelammert ao Projeto Ético de LIBERTAÇÃO FORMULADO POR DUSSEL}

\subsection{A CONSIDERAÇÃO DO SUJEITO VIVO E DE SUAS NECESSIDADES}

Em princípio, então, pode-se escolher qualquer fim tecnológica e economicamente possível. Contudo, o sujeito só pode atuar sendo sujeito vivo. E a vida requer condições materiais para ser possível. A escolha dos fins, portanto, necessariamente está subordinada à vida do sujeito. "Em consequiência, nem todos os fins tecnicamente concebíveis e naturalmente realizáveis, segundo o cálculo meio-fim, também são factíveis. Só é factível aquele subconjunto de fins que se integra em algum projeto de vida. Ou seja, fins não compatíveis com a manutenção da vida do próprio sujeito estão fora da factibilidade." ${ }^{48}$ Há algo mais do que uma racionalidade instrumental.

O problema é que nossa sociedade está centrada em um indivíduo calculista. Enquanto há adequação e eficiência, a ação é racional. Mas nesse sistema, deixa-se de lado a preocupação com os efeitos das ações sobre a sociedade e a natureza; o ser humano é simples peça do jogo. Quanto mais se guia pela racionalidade de cálculos meio-fim, menos se tem controle sobre os efeitos das ações. Esses efeitos acabam por gerar crises, como a exclusão de setores da população, devastação do meio ambiente etc. Aparece, então, o fenômeno da irracionalidade do racionalizado. "A ação é racional em termos de cálculo meio-fim, mas esse sistema de cálculo se revela como irracional." ${ }^{49}$ Perde-se a ética da responsabilidade e se funda uma ética da irresponsabilidade justificada apenas na eficiência. Isso ocorre com a atual inversão dos direitos humanos: em nome da proteção dos direitos humanos, acaba-se por se praticar condutas que ferem os direitos humanos (exemplos são as políticas contra o terrorismo) - é o irracional justificado e tomado como racional.

A ciência empírica apenas analisa as relações meio-fim e sua eficiência.

${ }^{48}$ Ibidem, p. 265.

${ }^{49}$ HINKELAMMERT, Franz J. La vuelta del sujeto humano reprimido frente a la estrategia de la globalización. In: FLORES, Joaquín Herrera (Ed.). El vuelo de anteo: derechos humanos y crítica de la razón liberal. Bilbao: Desclée de Brouwer, 2000. p. 208. Tradução livre. 
Hinkelammert reitera um bom exemplo. Uma pessoa está sentada sobre um galho de uma árvore alta. Em relação à racionalidade do corte do galho, pergunta-se se a serra está afiada, é utilizada da forma adequada, se o corte se dá no local adequado do galho etc. Uma serra elétrica é um meio tecnológica e economicamente possível para cortar o galho. Se alguém está sentado nesse galho que será serrado não é um problema nem de eficiência nem de racionalidade econômica. Contudo, o resultado alcançado será o ferimento ou a morte da pessoa devido à queda, e mesmo assim a ação seria racional. A morte contraria totalmente a ética, então a simples racionalidade instrumental não serve. O defeito da racionalidade estratégico-instrumental

é que é em si mesma cega ante os problemas da eficiência reprodutiva, e pode chegar ao absurdo de teorizar a forma mais eficiente de cortar o galho da árvore sobre o qual se está sentado. Concentra-se na operação meio-fim de uma ação, mas não pode refletir sobre a eficiência reprodutiva ou a racionalidade reprodutiva na qual, necessariamente, esta ação está inscrita. Então, não distingue entre galho da árvore no qual estou sentado e galhos nos quais não estou sentado. ${ }^{50}$

Uma simples racionalidade meio-fim não consegue evitar que se corte o galho no qual estou sentado. O grande desafio, então, é questionar o interesse calculado e desenvolver o critério da racionalidade reprodutiva. Há de se pensar em como produzir, reproduzir e desenvolver a vida humana.

Ainda, apenas em conjunto os homens podem viver. Assim, que o outro viva é condição da própria vida de cada sujeito. Nesse sentido, o assassinato é suicídio. A própria felicidade só é possível se o outro seja também feliz. O respeito real aos direitos humanos torna-se uma exigência ética ${ }^{51}$.

A necessidade de nova ética do "bem comum" é contribuição importantíssima da obra de Hinkelammert. O critério para estabelecer o que é possível e impossível é a

${ }^{50}$ HINKELAMMERT, Franz J. Claves de un pensamiento crítico. In: FLORES, Joaquín Herrera (Ed.). El vuelo de anteo: derechos humanos y crítica de la razón liberal. Bilbao: Desclée de Brouwer, 2000. p. 282. Tradução livre.

${ }^{51}$ HINKELAMMERT. La vuelta del sujeto humano reprimido ..., p. 214. Tradução livre. 


\section{A Contribuição Teórica de Franz Hinkelammert ao Projeto Ético de LIBERTAÇÃO FORMULADO POR DUSSEL}

reprodução da vida humana corporal e concreta. É possível julgar as instituições e ações conforme estejam ou não em função da vida dos sujeitos. Trata-se de uma ética concreta e real, calcada na satisfação das necessidades humanas.

Decorre da natureza humana o fato de que o sujeito tem necessidades vitais. "É preciso satisfazer as necessidades e, portanto, dirigir a escolha dos fins de modo que satisfaçam as necessidades, para que o conjunto da ação possa se manter no marco de algum projeto de vida." ${ }^{52} \mathrm{Na}$ escolha dos fins, deve-se considerar o critério de satisfação das necessidades (alimentação, vestuário, habitação etc.). Assim, é factível um meio tecnologicamente adequado, ajustado às condições econômicas e que satisfaça necessidades humanas vitais.

A satisfação das necessidades pressupõe o reconhecimento mútuo dos seres humanos como sujeitos. Assim, quando a realização de um valor leva ao sacrifício da vida de um sujeito, torna-se um antivalor. A realização de todo valor deve respeitar ao "não matarás" e por isso implica a realização da satisfação das necessidades básicas de todos.

Note-se que as preferências ou gostos não podem orientar os fins. "A satisfação das necessidades torna possível a vida; a satisfação das preferências a torna agradável. Mas para que ela possa ser agradável, antes tem que ser possível."53

Frente à exigência de satisfação das necessidades vitais, aparece o questionamento do capitalismo, pois se trata de modelo que nem sempre propicia a satisfação dessas necessidades e, em última instância, exclui a possibilidade de realização do projeto da vida.

\footnotetext{
${ }^{52}$ HINKELAMMERT. Crítica da razão utópica..., p. 266.

${ }^{53}$ Ibidem, p. 267.
} 


\title{
2.6 O AUTOMATISMO DO MERCADO E A NECESSIDADE DE PLANEJAMENTO ECONÔMICO
}

No capitalismo, o mercado é automático, movendo-se entre venda de produtos, rentabilidade de investimentos. Quanto mais se vendem produtos, maior a rentabilidade e maior a disponibilidade de capital para investimentos. Contudo, esse automatismo de mercado

\begin{abstract}
desemboca em completa arbitrariedade de distribuição de emprego, arbitrariedade que, por si mesma, implica a existência de tendência constante no sentido de distribuição de renda e de estrutura de emprego desequilibradas e economicamente irracionais. Conseqüentemente, o automatismo do mercado se transforma em mecanismo destruidor, enquanto ele impossibilita qualquer segurança de integração do sujeito econômico na divisão social do trabalho, através do emprego e da satisfação de suas necessidades. Até mesmo a própria subsistência é constantemente ameaçada e destruída. Esses desequilíbrios básicos se reproduzem em todos os níveis da sociedade capitalista, especialmente na relação entre o automatismo do mercado e o equilíbrio ecológico que, a longo prazo, é a base natural de qualquer possibilidade de satisfação das necessidades. À medida que prima o critério da rentabilidade, o equilíbrio ecológico é destruído, da mesma forma que o equilíbrio econômico-social da distribuição de renda e do emprego. ${ }^{54}$
\end{abstract}

Esse desequilíbrio e irracionalidade são efeitos não-intencionais da estrutura de mercado. Como ninguém deseja os desastres, eles são tidos como resultados naturais, que devem ser suportados. Contudo, Hinkelammert afirma que há sim responsabilidade humana em deixar continuar esse automatismo de mercado.

As ações muitas vezes têm efeitos não intencionais, que podem atentar contra a reprodução real da vida humana ecológica, biológica e social. São efeitos que desconsideram o fato de que a realidade é condição de possibilidade da vida humana. Portanto, ao considerar as possibilidades de êxito das ações intencionais, é preciso considerar também os possíveis efeitos não intencionais. Exemplos desses efeitos do sistema capitalista são: miséria, desemprego, subdesenvolvimento e a exclusão de grupos sociais, violações aos direitos humanos. Como são efeitos não intencionais, não

\footnotetext{
${ }^{54}$ Ibidem, p. 269-270.
} 


\section{A Contribuição Teórica de Franz Hinkelammert ao Projeto Ético de LIBERTAÇÃO FORMULADO POR DUSSEL}

bastam boas intenções para solucioná-los, e sim uma mudança institucional e estrutural no sentido de que todo ser humano tenha a possibilidade de se integrar na comunidade por seu próprio trabalho e viver uma vida digna, satisfazendo, ao menos, suas necessidades básicas.

Existe uma responsabilidade frente à capacidade de convivência humana, já que não se pode assegurar a vida destruindo a vida do outro. Nesse sentido, Hinkelammert propõe não só realizar uma análise crítica, mas também oferecer resistência às consequiências danosas, mediante a elaboração de uma ética do bem comum, assegurando-se as condições de possibilidade da vida humana. Isso implica uma mudança das relações sociais de produção capitalistas, pois o automatismo do mercado contém a tendência a desequilíbrios. Deve-se controlar o mercado para evitar esses desequilíbrios, e isso se faz com um planejamento adequado.

Para alcançar, então, algum grau de racionalidade econômica torna-se imprescindível e obrigatório o planejamento econômico, que não é noção oposta à de mercado. Com o planejamento, evitam-se ou colocam-se em marcos toleráveis as crises econômicas e sociais provenientes do automatismo de mercado, possibilitando uma distribuição de renda adequada à satisfação das necessidades e uma estrutura de pleno emprego.

Falou-se da necessidade do planejamento, sem com isso excluir o mercado. Uma relação de equilíbrio deve contemplar o planejamento e as relações de mercado, ambas de maneira delimitada. Hinkelammert formula um princípio de delimitação:

o planejamento tem que se estender em tal grau que possa assegurar o equilíbrio econômico da divisão social do trabalho, nos termos do pleno emprego garantido para todos e de correspondente satisfação de suas necessidades vitais como resultado de seu trabalho. Não há nenhuma razão para estender o planejamento econômico além desse ponto, mas de forma alguma ele pode abranger menos do que isso. Esse mesmo critério delimita a autonomia empresarial, que não pode indicar um âmbito além daquele que permite garantir a reprodução da vida real de todos por meio do planejamento, embora também não haja qualquer razão para que o âmbito seja menor do que esse. ${ }^{55}$

${ }^{55}$ Ibidem, p. 278-279. 
"Trata-se de critério que poderia ser resumido nos seguintes termos: $a$ liberdade de cada um tem que ser restringida de tal modo a não pôr em perigo a base real do exercício da liberdade de qualquer outro. Assim, o limite da liberdade de cada um é a garantia da base real de reprodução da vida de cada um" ${ }^{\text {56 }}$. O norte para os projetos e as autonomias é a vida real.

Como a satisfação das necessidades é institucionalizada, surge o sujeito da práxis. A práxis "significa assegurar ao sujeito humano uma institucionalidade que garanta a possibilidade de seu desenvolvimento e, por conseguinte, a possibilidade de realizar efetivamente um projeto de vida num quadro de condições materiais asseguradas." $^{57}$ Há a necessidade de institucionalizações para satisfazer as necessidades vitais. Esse sujeito da práxis é o sujeito livre, com condições de viver.

\subsection{UM ESPAÇO DE REFLEXÃO ENTRE O POSSÍVEL E O IMPOSSÍVEL}

Hinkelammert conclui que "Os princípios de impossibilidade das ciências empíricas descrevem impossibilidades para a ação humana, mas aquilo que afirmam como impossível não é logicamente contraditório." ${ }^{58}$ Assim, há um espaço entre o que está (além do) humanamente possível e entre o que é logicamente contraditório, um conjunto de mundos pensáveis, um espaço teológico. É preciso pensar o impossível, pois sem fazê-lo não se pode conhecer o possível; então esse impossível tem que ser de alguma forma possível, embora não o seja pela ação humana. As explicações podem ser teológicas (nada para Deus é impossível) ou ilusões humanas.

Segundo o juízo constituinte do espaço teológico, "aquilo que é humanamente

\footnotetext{
${ }^{56}$ Ibidem, p. 279.

${ }^{57}$ Ibidem, p. 282.

${ }^{58}$ Ibidem, p. 299.
} 


\section{A Contribuição Teórica de Franz Hinkelammert ao Projeto Ético de LIBERTAÇÃO FORMULADO POR DUSSEL}

impossível, apesar de tudo, é possível. Trata-se de um juízo ontológico, não justificável a partir das ciências empíricas, mas que, sem dúvida, encontra-se em relação de coerência e complementaridade com elas." ${ }^{59}$

\section{O APORTE TEÓRICO DE HINKELAMMERT COMO MEDIAÇÃO NECESSÁRIA À ÉTICA DA LIBERTAÇÃO}

$\mathrm{Na}$ arquitetônica da ética da libertação, a factibilidade ou realizabilidade dos atos verdadeiros e válidos é fundamental. O objeto, na prática, deve ser possível nos diversos níveis de análise (lógica, empírica, técnica, econômica e ética). Para determinar-se o que pode ser feito, a razão estratégico-instrumental é útil e necessária, mas insuficiente. "A razão instrumental deverá estar sobredeterminada por exigências de verdade prática (reprodução e desenvolvimento da vida do sujeito humano) e de validade intersubjetiva." ${ }^{60}$ Pois "quando o critério da factibilidade é elevado à condição de 'princípio absoluto' cai-se nas reduções já conhecidas desde o paradigma da modernidade, com destaque principal à matriz positivista. Porém, na dialeticidade das racionalidades em jogo, os momentos - o material e o formal - ao subsumirem o critério da factibilidade transformam-no em princípio de operabilidade ou princípio ético de factibilidade." ${ }^{61}$ Os três momentos da ética da libertação interagem, fazendo com que a factibilidade torne-se princípio ético de factibilidade. Concluindo que algo pode ser feito, cabe agora extrair o que deve necessariamente ser feito, por uma questão ética. Por exemplo, as necessidades humanas básicas devem ser satisfeitas para manter a vida. O princípio de operabilidade é assim enunciado:

\footnotetext{
${ }^{59}$ Ibidem, p. 307.

${ }^{60}$ LUDWIG, op. cit., p. 303.

${ }^{61}$ Idem.
} 
Aquele que opera ou decide eticamente uma norma, instituição ou eticidade sistêmica deve cumprir: (a) com as condições de factibilidade lógica e empírica (técnica, econômica, política, cultural, etc.), isto é, que seja realmente possível em todos esses níveis, a partir do marco (b) das exigências: (b.1) ético-materiais da verdade prática e (b.2) morais-formais discursivas da validade, dentro de uma escala que vai desde (bi) as ações permitidas eticamente (que são as meramente "possíveis", que não contradizem os princípios ético ou moral) até (b.ii) as ações devidas (que são as eticamente "necessárias" ao cumprimento das exigências humanas básicas: materiais - de reprodução e desenvolvimento da vida do sujeito humano - ou formais - desde o respeito da dignidade de todo sujeito ético até a participação da vida do sujeito humano - ou formais - desde o respeito da dignidade de todo sujeito ético até a participação efetiva e simétrica dos afetados nas decisões). ${ }^{62}$

A mediação de Franz Hinkelammert revela-se de suma importância na ética da libertação formulada por Dussel, pois afirma a impossibilidade de apreensão da realidade, ressaltando a limitação das ações humanas. Não se pode pensar em utopias ingênuas, e sim no que é possível fazer. Esse possível depende da tecnologia, do momento civilizatório, mas deve principalmente considerar o respeito ao sujeito vivo e à satisfação das necessidades humanas básicas. Dessa forma, Hinkelammert insere um conteúdo ético na racionalidade instrumental, valorizando a vida do sujeito e impedindo que os fins sejam alcançados por qualquer meio. Assim, Hinkelammert contribui fortemente para a concretização do objetivo da ética da libertação: libertar as vítimas das situações de negatividade e construir utopias possíveis em que as pessoas vivam e sejam respeitadas plenamente.

\section{REFERÊNCIAS}

DUSSEL, Enrique. Ética da libertação - na idade da globalização e da exclusão. Petrópolis: Vozes, 2000.

HINKELAMMERT, Franz J. Claves de un pensamiento crítico. In: FLORES, Joaquín Herrera (Ed.). El vuelo de anteo: derechos humanos y crítica de la razón liberal.

${ }^{62}$ DUSSEL, Enrique. Ética da Libertação - na idade da globalização e da exclusão. Petrópolis: Vozes, 2000. p. 272. 


\section{A Contribuição Teórica de Franz Hinkelammert ao Projeto Ético de LIBERTAÇÃO FORMULADO POR DUSSEL}

Bilbao: Desclée de Brouwer, 2000. p. 267-303. Entrevista.

Crítica da razão utópica. São Paulo: Paulinas, 1986.

- La vuelta del sujeto humano reprimido frente a la estrategia de la globalización. In: FLORES, Joaquín Herrera (Ed.). El vuelo de anteo: derechos humanos y crítica de la razón liberal. Bilbao: Desclée de Brouwer, 2000. p. 203-214.

LUDWIG, Celso Luiz. A transformação jurídica na ótica da filosofia transmoderna: a legitimidade dos novos direitos. Revista da Faculdade de Direito da Universidade Federal do Paraná, Curitiba, n. 41, p. 29-42, 2004.

Da ética à filosofia política crítica na transmodernidade: reflexões desde a filosofia de Enrique Dussel. In: FONSECA, Ricardo Marcelo (org). Repensando a Teoria do Estado. Belo Horizonte: Fórum, 2004. p. 283-325.

MARRAFON, Marco Aurélio. Para além do consenso: Dussel e a possibilidade de uma fundamentação ética para uma teoria crítica do direito constitucional. In: NUNES, António José Avelãs; COUTINHO, Jacinto Nelson de Miranda. Diálogos constitucionais: Brasil/Portugal. Rio de Janeiro: Renovar, 2004. p. 387-416.

RUBIO, David Sanchez. Resenha. Revista Crítica Jurídica, n. 20, jan./ jul./2002. 